\title{
Refractory plasmonics enabling $20 \%$ efficient lead-free perovskite solar cells
}

\begin{abstract}
Ahmed A. Mohsen ${ }^{1,2}$, Mohamed Zahran², S. E. D. Habib ${ }^{3}$ \& Nageh K. Allam $\mathbb{1}^{1 *}$
Core-shell refractory plasmonic nanoparticles are used as excellent nanoantennas to improve the efficiency of lead-free perovskite solar cells (PSCs). $\mathrm{SiO}_{2}$ is used as the shell coating due to its high refractive index and low extinction coefficient, enabling the control over the sunlight directivity. An optoelectronic model is developed using 3D finite element method (FEM) as implemented in COMSOL Multiphysics to calculate the optical and electrical parameters of plain and $\mathrm{ZrN} / \mathrm{SiO}_{2}$-modified PSCs. For a fair comparison, $\mathrm{ZrN}$-decorated PSCs are also simulated. While the decoration with $\mathrm{ZrN}$ nanoparticles boosts the power conversion efficiency (PCE) of the PSC from $12.9 \%$ to $17 \%$, the use of $\mathrm{ZrN} / \mathrm{SiO}_{2}$ core/ shell nanoparticles shows an unprecedented enhancement in the PCE to reach $20 \%$. The enhancement in the PCE is discussed in details.
\end{abstract}

The promising efficiency and affordable cost are the driving forces pushing the research on lead $(\mathrm{Pb})$-based perovskite solar cells (PSCs) over the past decade ${ }^{1-5}$. The latest power conversion efficiency (PCE) certified by the National Renewable Energy Laboratory (NREL) for PSCs is $24.2 \%$ as reported by KRICT/MIT ${ }^{6}$, competing that of Si-based photovoltaic and surpassing CdTe solar cells ${ }^{7,8}$. However, the toxicity concerns of $\mathrm{Pb}$ were proved to be a serious flaw and can hurdle the path of PSCs towards commercialization ${ }^{9-12}$. Partial replacement of $\mathrm{Pb}$ with lower toxicity cations has been reported and proposed as $\mathrm{Ge}^{13}, \mathrm{Sb}^{14}$, and $\mathrm{Sn}^{15,16}$. Among those candidates, $\mathrm{Sn}$ has shown a close similarity to $\mathrm{Pb}^{17}$ with a remarkable enhancement in PCE from $6 \%{ }^{16}$ to $10 \%{ }^{18}$. However, this PCE is much lower than that reported for Pb-based PSCs, leaving a room for improvement. Generally, the lack of light absorption is the major concern hindering the achievement of high PCE for thin film solar cells (TFSCs) due to the small thickness of the active layer used. In this regard, the use of plasmonic light trapping nanoparticles has emerged as a means to enhance the PCE of TFSCs ${ }^{19-22}$. Plasmonic nanoparticles act as nanoantennas that couple near field electromagnetic waves (sunlight) to sub-wavelength area, enhancing the nanoscale light-material interactions $^{23-25}$. The geometry, dielectric permittivity, surface roughness, and surrounding medium are the factors determining the plasmonic near-field intensity. To this end, noble metal nanoparticles (Au, Ag, etc.) have been reported to enhance the efficiency of TFSCs ${ }^{26,27}$ due to their ability to couple electromagnetic waves at air/metal interactions using surface plasmon guided modes and control the direction of scattered light ${ }^{28,29}$. However, noble metals are expensive, exhibit narrow-band scattering and absorption spectra, thermally unstable, and CMOS incompatible. As alternatives, refractory plasmonic metal nitrides such as TiN and $\mathrm{ZrN}$ have been investigated with promising results being reported that were ascribed to their highly tunable optoelectronic characteristics ${ }^{30-34}$ Of special interest, plasmonic/dielectric core/shell nanostructures have attracted recent attention mainly due to the fact that dielectrics are transparent to sunlight and enjoy high refractive index that enables the control over light coupling ${ }^{35}$ and the possibility of tuning the surface plasmon resonance ${ }^{36}$. The use of core-shell structure provides both electrical and chemical protection isolation to the plasmonic core as it prevents the metal diffusion contaminant into the solar cell structure.

Herein, we show the opportunity to boost the efficiency of $\mathrm{Pb}$-free perovskite solar cells (PSCs) to reach up to $20 \%$ upon the implantation of $\mathrm{ZrN} / \mathrm{SiO}_{2}$ core/shell nanoparticles in the active layer. For comparison, $\mathrm{ZrN}$ and TiN-decorated PSCs have also been investigated and discussed.

\footnotetext{
${ }^{1}$ Energy Materials Laboratory (EML), School of Sciences and Engineering, The American University in Cairo, New Cairo, 11835, Egypt. ${ }^{2}$ Nanotechnology Laboratory, Electronics Research Institute, Cairo, Egypt. ${ }^{3}$ Electronics and Communications, Faculty of Engineering, Cairo University, Giza, Egypt. *email: nageh.allam@aucegypt.edu
} 

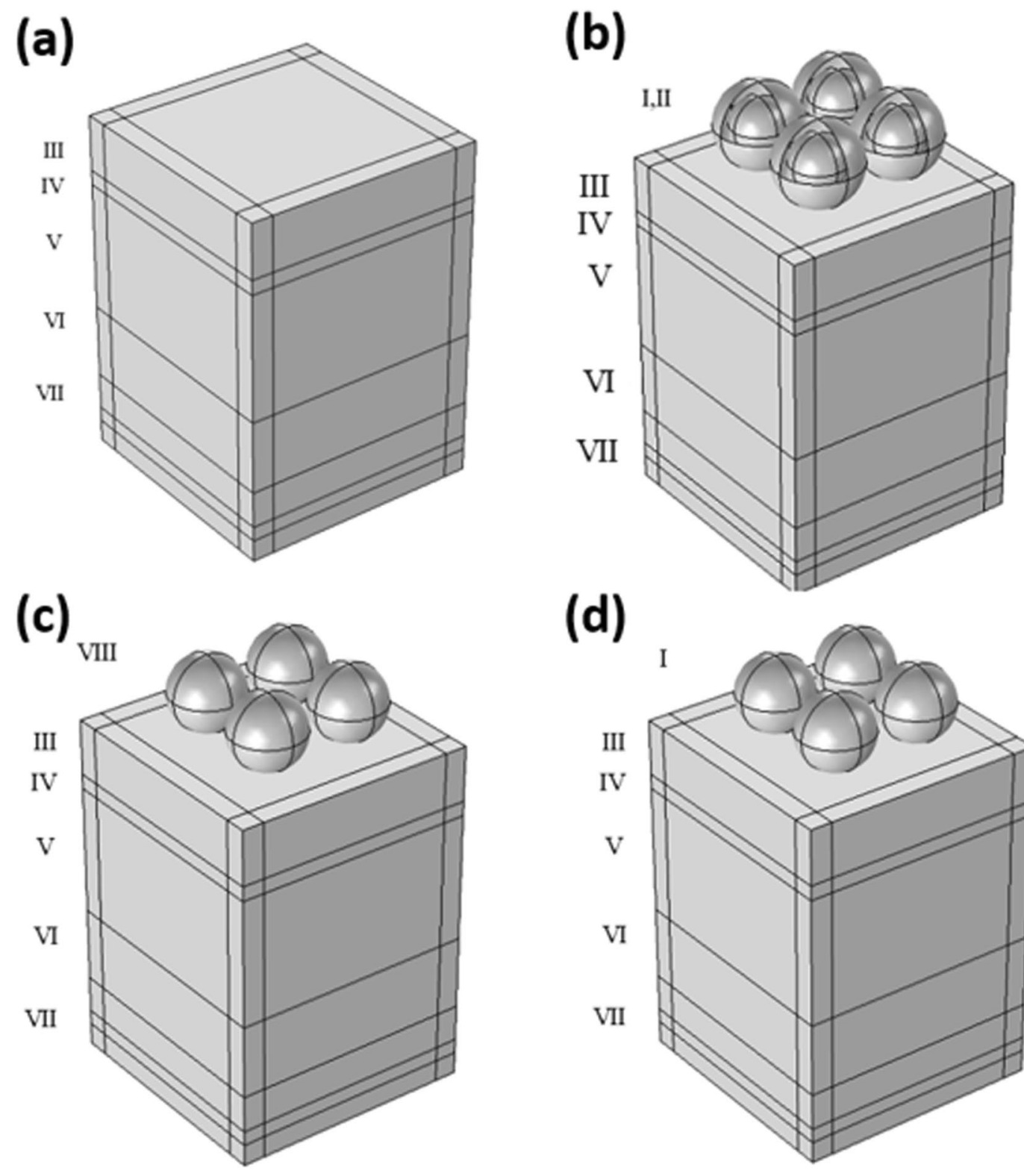

(d)

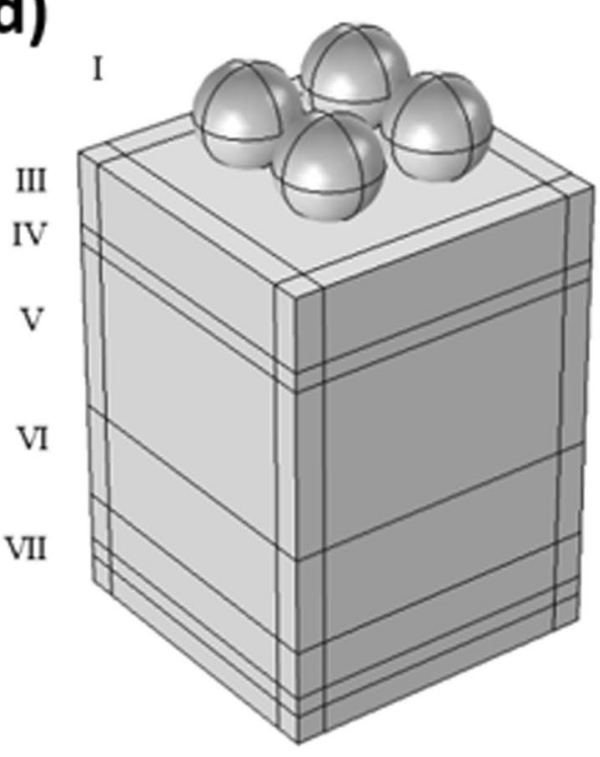

Figure 1. (a) Planar perovskite solar cell structure consisting of (VII) gold (Au) as a back contact with a thickness of $100 \mathrm{~nm}$, (VI) HTM (Spiro-OMeTAD) with a thickness of $200 \mathrm{~nm},(\mathrm{~V}) \mathrm{MASnI}_{3}$ active material with a thickness $350 \mathrm{~nm}$, (IV) ETM ( $\mathrm{TiO}_{2}$ ) with thickness of $40 \mathrm{~nm}$, and (III) ITO with thickness of $150 \mathrm{~nm}$. (b) planar perovskite with the core-shell nanoparticles consisting of (I) $\mathrm{ZrN}$ nanoparticles as a plasmonic core and shielded by (II) $\mathrm{SiO}_{2}$ nanoshells with thickness of $40 \mathrm{~nm}$. (c) planar perovskite solar cell implanted above ITO are the (VIII) TiN nanoparticles. (d) planar perovskite solar cell implanted above ITO are the (I) ZrN nanoparticles, the proposed solar cell structure is of width and depth of $600 \mathrm{~nm}$.

\section{Optoelectronic Modeling Details}

Four 3D electromagnetic wave (EMW) models have been constructed based on finite element method (FEM). The first model is used to calculate the interaction of sunlight electromagnetic radiation (AM 1.5 G) with solar cell active layers based on Maxwell's equations of light propagation:

$$
\begin{gathered}
\frac{\partial H}{\partial t}=\frac{-1}{\mu} \nabla \times E \\
\varepsilon \frac{\partial E}{\partial t}=\nabla \times H-\sigma E
\end{gathered}
$$

where $H$ is the magnetic field, $E$ is the electric field, $\mu$ is the permeability, $\mathcal{E}$ is the electric permittivity, and $\sigma$ is the electric conductivity. This model is used to develop the full field of the proposed design in Fig. 1a of planar 
(a)

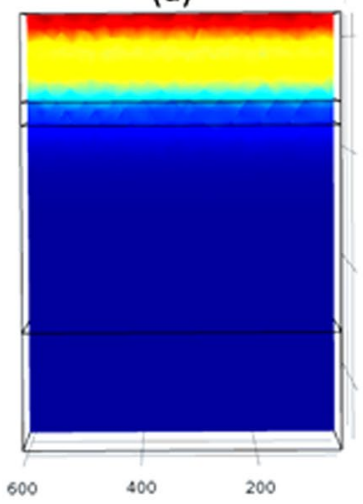

(c)

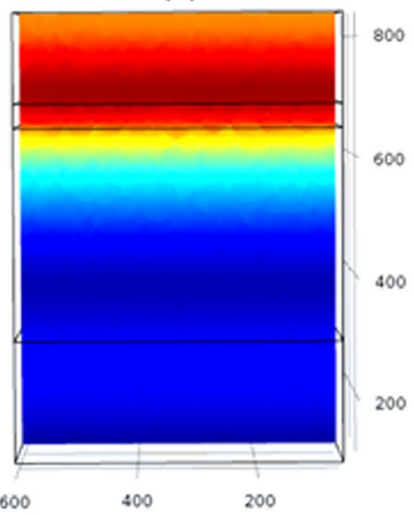

(b)
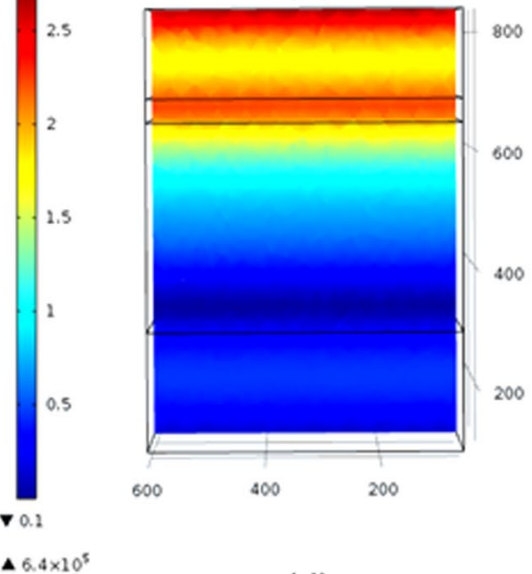

$6.4 \times 10^{5}$
$\times 10^{5}$

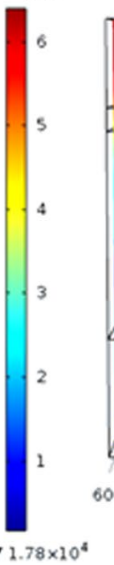

(d)

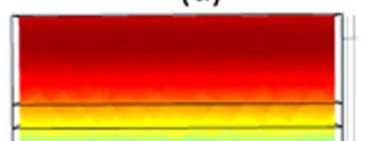

800

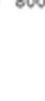

600

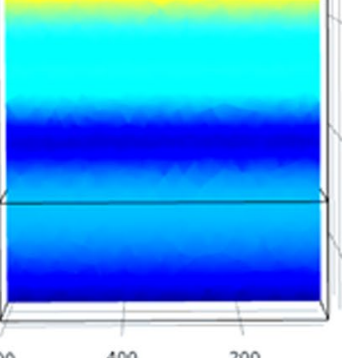

200
200

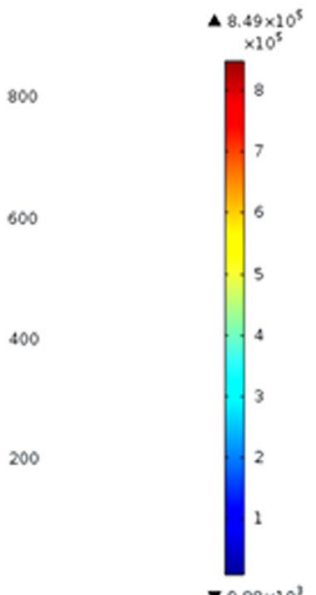

A $5.42 \times 10^{5}$ $\times 20^{5}$

4.5

3.5

3

25

1.5

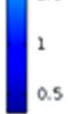

> $3.18 \times 10^{4}$

Figure 2. Electric field profiles at different wavelengths: (a) $300 \mathrm{~nm}$, (b) $800 \mathrm{~nm}$, (c) $1000 \mathrm{~nm}$, and (d) $1200 \mathrm{~nm}$ for planar PSCs.

perovskite solar cell in order to obtain the generation rate and short circuit current $(J s c)$. The optical carrier generation rate $\left(G_{o p t}\right)$ per wavelength over the active layer volume is calculated using Eq. $3^{37}$.

$$
G_{o p t}(\lambda)=\frac{\varepsilon^{\prime \prime}|E|^{2}}{2 \hbar}
$$

where the optical carrier generation depends on the complex permittivity imaginary part $\left(\varepsilon^{\prime \prime}\right)$ and the electric field intensity. Upon integrating the optical carrier generation over the simulated wavelength $(\lambda)$, the total generation rate (TGR) can be estimated using Eq. 4 .

$$
T G R=\int_{\lambda_{1}}^{\lambda_{2}} G_{o p t}(\lambda) d \lambda
$$

where $\lambda_{1}$ and $\lambda_{2}$ are the minimum and maximum of simulated wavelengths that have been swept over the optical model, respectively. The second and third models are based on coupling the optoelectrical model with the first model as we used the full field of the planar model as an input to simulate the nanostructured refractory plasmonics model. TiN and $\mathrm{ZrN}$ nanoparticles were used as nanoscatterers with different radii $(50 \mathrm{~nm}, 75 \mathrm{~nm}, 100 \mathrm{~nm})$ on the top of the Sn-based perovskite solar cell and compare the emerged plasmon enhancements with respect to the planar model. The proposed design of TiN and ZrN nanoparticles are shown in Fig. 1b,c. The normalized light absorption profile was calculated using Eq. $5^{38}$.

$$
\text { Normalized Absorption }=\frac{\text { Absorption of nanostructured film }}{\text { Absorption of planar film }}
$$

The fourth model proposes a novel design of $\mathrm{ZrN}$ nanoparticles with different radii $(50 \mathrm{~nm}, 75 \mathrm{~nm})$ as a plasmonic core and $\mathrm{SiO}_{2}$ as a dielectric shell of thickness $40 \mathrm{~nm}$. The proposed design is shown in Fig. $1 \mathrm{~d}$.

The external quantum efficiency $(E Q E)$ was calculated for the planar, TiN, and $\mathrm{ZrN}$ nanostructured solar cells using Eq. $6^{38}$ assuming single-path absorption and unit internal quantum efficiency (IQE). 

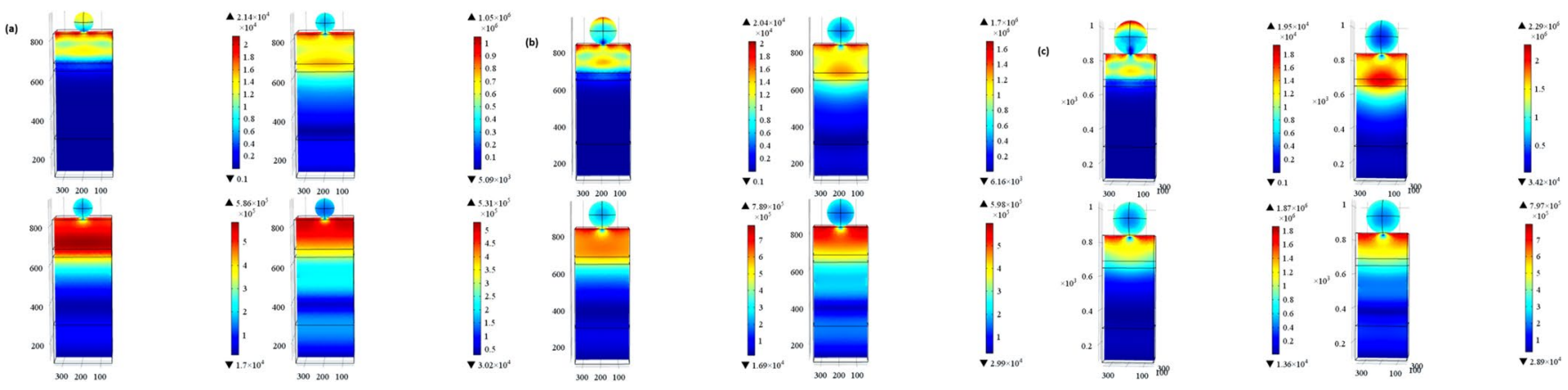

Figure 3. Electric field profiles at different wavelengths: (a) $300 \mathrm{~nm}$, (b) $800 \mathrm{~nm}$, (c) $1000 \mathrm{~nm}$, and (id) $1200 \mathrm{~nm}$ for (a) $50 \mathrm{~nm}$, (b) $75 \mathrm{~nm}$, and (c) $100 \mathrm{~nm}$ TiN nanoparticles-decorated PSCs, respectively.
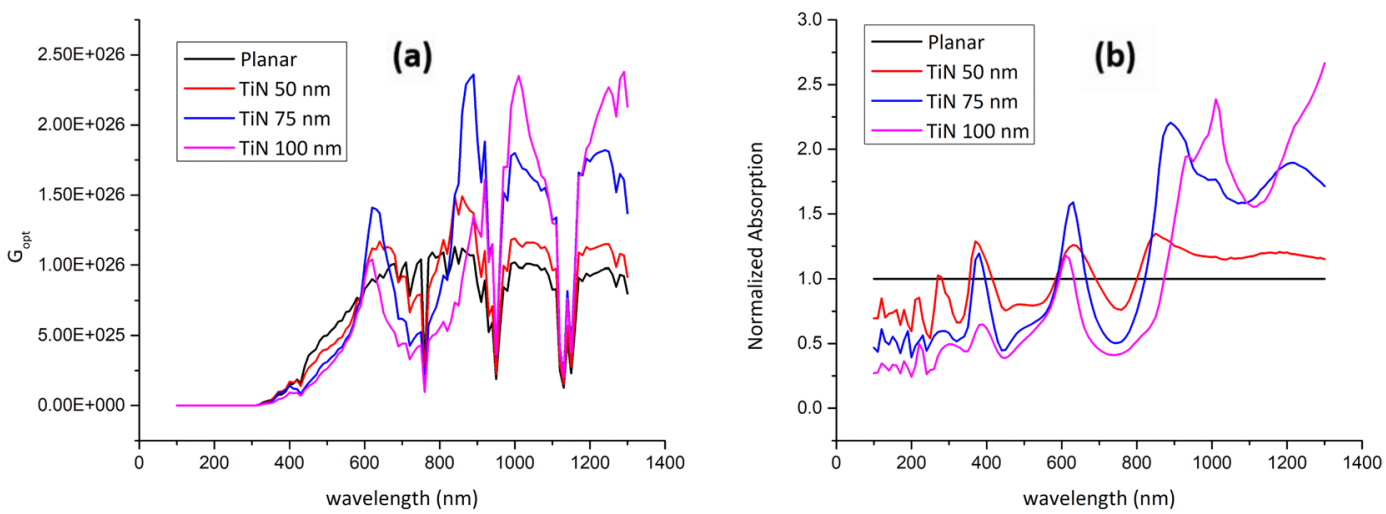

Figure 4. (a) Optical carrier generation rate $\left(G_{o p t}\right)$ and (b) normalized light absorption profiles for planar and TiN-decorated PSCs.

\begin{tabular}{|l|l|l|l|l|l|l|}
\hline Structure & TGR $\left(\mathbf{m}^{-3} \mathbf{s}^{-1}\right)$ & TGR Enhancement & $\boldsymbol{J}_{\boldsymbol{s c}}\left(\mathbf{m A} / \mathbf{c m}^{2}\right)$ & $\boldsymbol{V}_{\boldsymbol{o c}}(\mathbf{m V})$ & $\boldsymbol{F F}(\%)$ & $\boldsymbol{P C E}(\%)$ \\
\hline Planar & $7.1840 \times 10^{27}$ & --- & 27 & 680.47 & 70.21 & 12.9 \\
\hline $\operatorname{TiN}(50 \mathrm{~nm})$ & $7.9038 \times 10^{27}$ & $10.02 \%$ & 29.71 & 683.50 & 70.64 & 14.3 \\
\hline $\operatorname{TiN}(75 \mathrm{~nm})$ & $9.225 \times 10^{27}$ & $28.4 \%$ & 34.7 & 687.57 & 71.23 & 17 \\
\hline $\operatorname{TiN}(100 \mathrm{~nm})$ & $9.8205 \times 10^{27}$ & $36.7 \%$ & 36.91 & 689.2 & 71.48 & 18.2 \\
\hline
\end{tabular}

Table 1. Optical and electrical parameters for planar and TiN-implanted PSCs.

$$
\mathrm{EQE}=\mathrm{IQE} * \text { Absorption }
$$

The optical refractive indices and extinction coefficients of $\mathrm{Au}, \mathrm{MASnI}_{3}, \mathrm{TiO}_{2}$, Spiro-OMeTAD, ITO, TiN, and $\mathrm{ZrN}$ were taken from previously published data ${ }^{39-45}$. The electrical model was based on the use of the $G_{o p t}$ as an input parameter. The current-voltage characteristics were obtained by solving the drift-diffusion and 3D Poisson's equations. Series and Shunt resistances were used as fitting parameters from previously measured data ${ }^{46}$. The $J_{s c}$ was calculated using Eq. $7^{47}$.

$$
J_{s c}=q \int_{\lambda_{1}}^{\lambda_{2}} \frac{A M 1.5 G(\lambda) \times(1-\exp (-\alpha d))}{\frac{h c}{\lambda}} d \lambda
$$

where $q$ is the elementary charge, $d$ is the thickness of the active layer, and $\alpha$ is the absorption coefficient calculated using Eq. 8.

$$
\alpha(\lambda)=\frac{4 \pi k(\lambda)}{\lambda}
$$

where $k(\lambda)$ is the extinction coefficient for each simulated wavelength. As $J_{s c}$ is directly proportional to the total carrier generation rate and have the same dimensions of the planar model, Eq. 9 can be used to calculate any enhancement in $J_{s c}{ }^{48}$. 


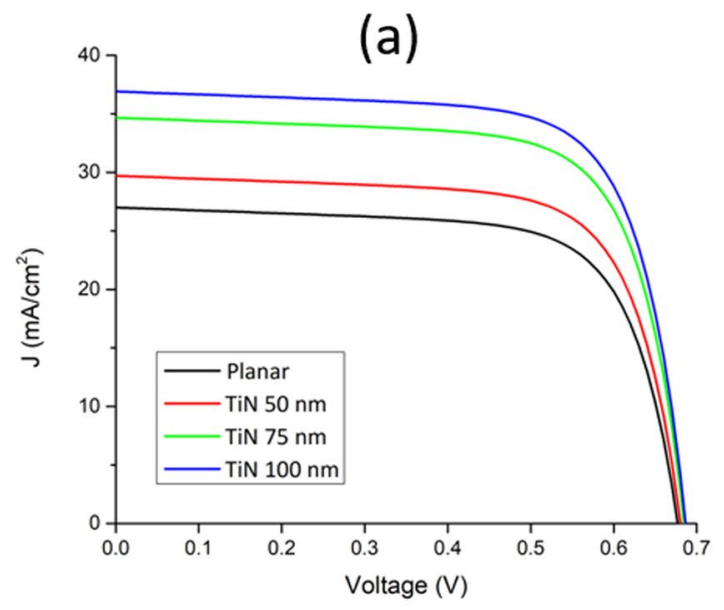

(b)
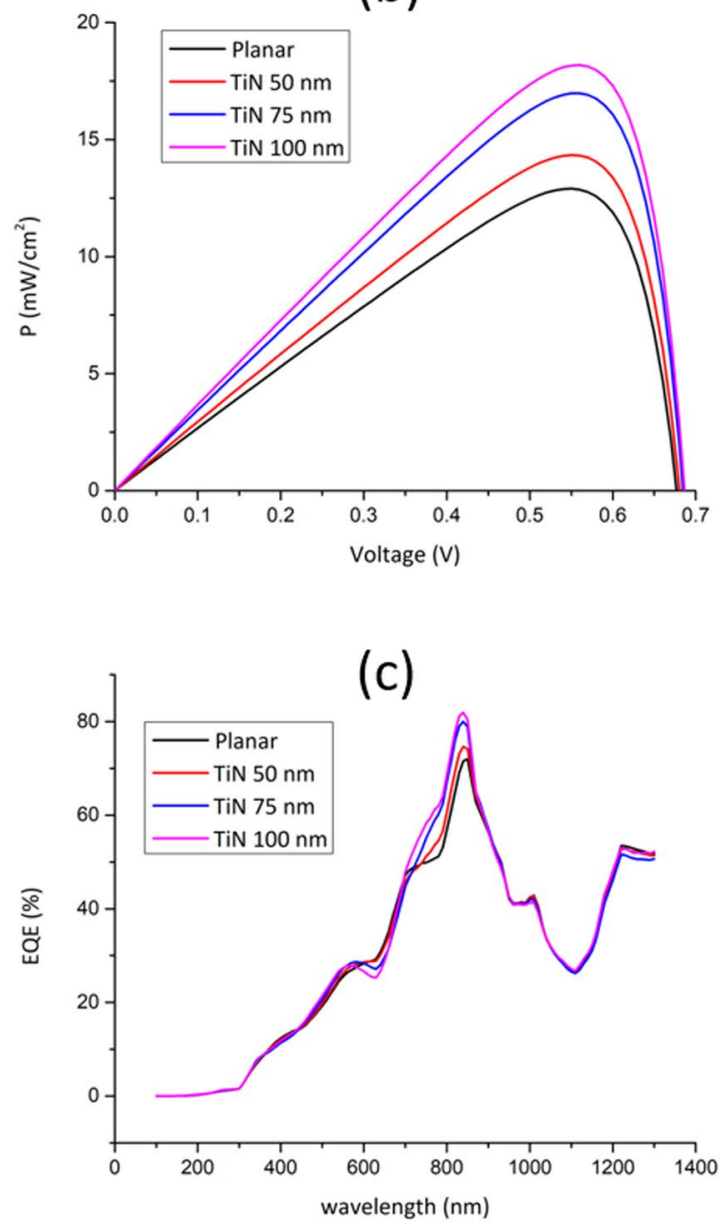

Figure 5. (a) $J-V$, (b) $P-V$, and $E Q E$ characteristics of the proposed PSCs.

$$
J_{s c} \text { enhancement }=\frac{\text { Total Generation Rate using nanostructures }}{\text { Total Generation Rate of planar cell }}
$$

The COMSOL Multiphysics software package was used with AM $1.5 \mathrm{G}$ as an input power port and a wavelength in the range $100-1300 \mathrm{~nm}$ was swept over with $10 \mathrm{~nm}$ step size in order to cover the UV, visible, and IR regions to obtain the greatest possible plasmonic enhancement over the whole possible simulated bandwidth because TiN and ZrN nanoparticles have an increasing extinction coefficient in the IR bandwidth ${ }^{44,45}$. The optoelectrical model was applied on a cell surrounded by perfectly matched layers (PMLs) in all directions and periodic boundary conditions (PBCs) in $\mathrm{x}-\mathrm{y}$ direction. However, there were some hurdles in the optical 
(a)
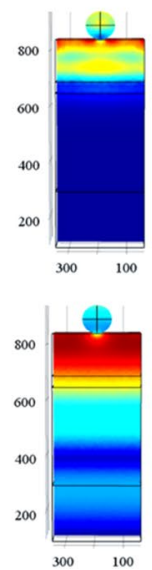

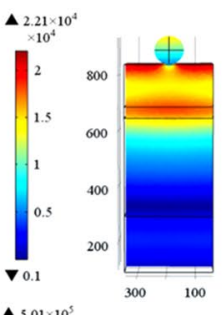

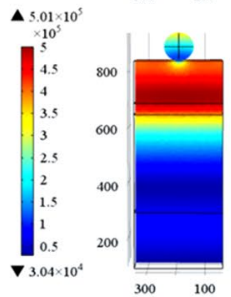

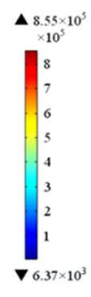

$\Delta .86 \times 10^{5}$

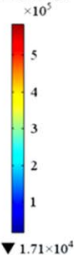

(b)
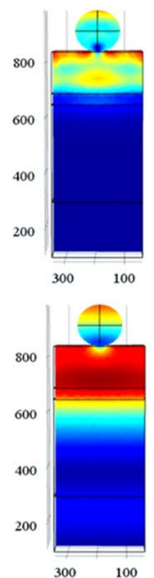
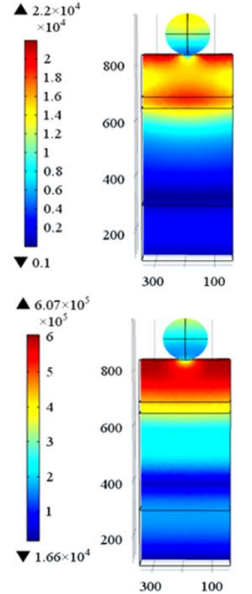
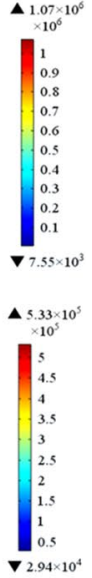

Figure 6. Electric field profiles of the $\mathrm{ZrN}$-decorated PSCs: $\mathrm{ZrN}$ radii (a) $50 \mathrm{~nm}$ (b) $75 \mathrm{~nm}$, and (c) $100 \mathrm{~nm}$ at wavelengths of $300 \mathrm{~nm}, 800 \mathrm{~nm}, 1000 \mathrm{~nm}$, and $1200 \mathrm{~nm}$, respectively.
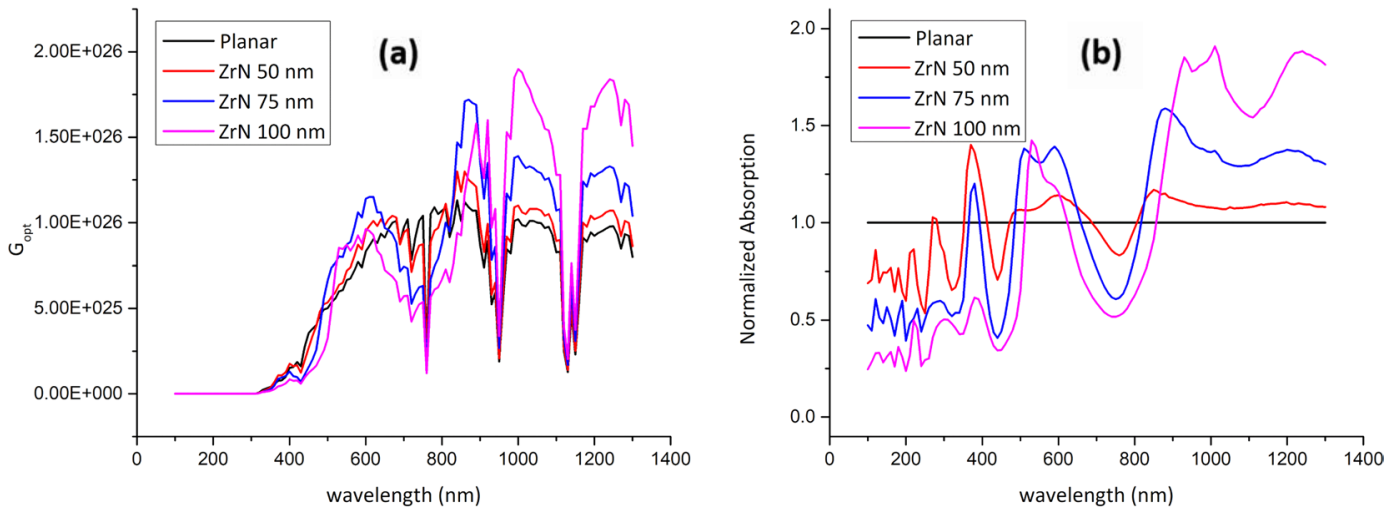

Figure 7. (a) Optical carrier generation rate $\left(G_{o p t}\right)$ and $(\mathbf{b})$ normalized light absorption profiles for planar and ZrN-decorated PSCs.

\begin{tabular}{|l|l|l|l|l|l|l|}
\hline Structure & TGR $\left(\mathbf{m}^{-3} \mathbf{s}^{-1}\right)$ & TGR Enhancement & $\mathbf{J}_{\mathbf{s c}}\left(\mathbf{m A} / \mathbf{c m}^{2}\right)$ & $\mathbf{V}_{\text {oc }}(\mathbf{m V})$ & FF $(\%)$ & PCE $(\%)$ \\
\hline Planar & $7.1840 \times 10^{27}$ & --- & 27 & 680.5 & 70.21 & 12.9 \\
\hline $\mathrm{ZrN}(50 \mathrm{~nm})$ & $7.6106 \times 10^{27}$ & $5.9 \%$ & 28.8 & 681.9 & 70.48 & 13.7 \\
\hline $\mathrm{ZrN}(75 \mathrm{~nm})$ & $8.5930 \times 10^{27}$ & $19.6 \%$ & 32.6 & 685.1 & 70.96 & 15.7 \\
\hline $\mathrm{ZrN}(100 \mathrm{~nm})$ & $9.0375 \times 10^{27}$ & $25.8 \%$ & 34.2 & 686.4 & 71.14 & 16.6 \\
\hline
\end{tabular}

Table 2. The optical and electrical parameters of the $\mathrm{ZrN}$-decorated PSCs.

model. First, the largest value allowed for mesh size must not exceed $\lambda / 10$ of the smallest simulated wavelength. Therefore, a tetrahedron shape was selected for meshing the solar cell active layers, where the smaller the mesh size, the more accurate the computational data compared to the practical counterpart. However, this comes on the expense of the computational time. Second, in order to decrease the computational time, a mapped meshing with normal or coarse meshing was applied to the PMLs surrounding the solar cell in order to allow the use of smaller mesh size for the solar cell and the active material. Third, the $G_{o p t}$ was integrated to the full simulated bandwidth and used as an input data profile to construct the electrical model. In the electrical model, any enhancements in light absorption was assumed to be directly proportional to the enhancements in the photocurrent as shown by Eq. 9. The electrical parameters of $\mathrm{TiO}_{2}, \mathrm{MASnI}_{3}$, and Spiro-OMeTAD were extracted from literature ${ }^{49,50}$.

\section{Results and discussion}

Nanoparticles-decorated PSCs. To construct the optoelectrical model of the TiN or ZrN-decorated PSCs, the optoelectrical model for plain (planar) solar cell is developed first to calculate the $G_{o p t}$ and $J_{s c}$ for planar PSC for better comparison. The proposed design is shown in Fig. 1a, where the thicknesses of Au, Spiro-OMeTAD, $\mathrm{MASnI}_{3}, \mathrm{TiO}_{2}$, and ITO layers are $100 \mathrm{~nm}, 200 \mathrm{~nm}, 40 \mathrm{~nm}, 350 \mathrm{~nm}$, and $150 \mathrm{~nm}$, respectively with $600 \mathrm{~nm}$ width 

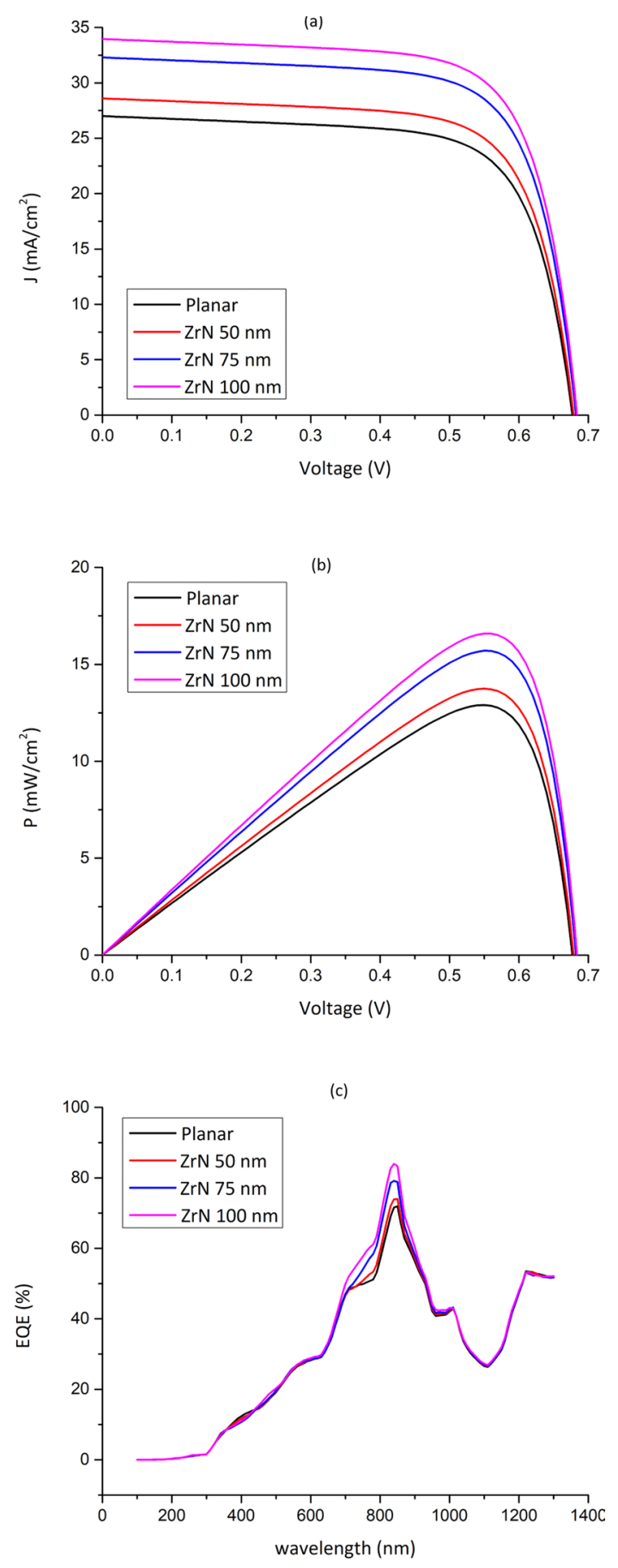

Figure 8. (a) $J-V$, (b) $P-V$, and $E Q E$ characteristics of the proposed PSCs.

and $600 \mathrm{~nm}$ depth. The electric field profiles are investigated at selected wavelengths that represent the UV, visible, and IR bandwidths (i.e. full bandwidth scan). The electric field profiles of the planar perovskite solar cell are shown in Fig. 2.

TiN-decorated PSCs. TiN nanoparticles were implanted on-top of the PSC active layer as discussed in model 2 and shown in Fig. 1b. Figure 3 shows the electric field profiles upon implanting TiN nanoparticles and their electromagnetic radiation resonance coupling enhancement to the solar cell active layers, which glows the most in the IR range compared to the planar PSCs counterparts. For each simulated TiN nanoparticles' size, the corresponding $G_{\text {opt }}$ is calculated using Eq. 3 and plotted in Fig. 4a. TiN acts as an absorber in the bandwidth range $300 \mathrm{~nm}-580 \mathrm{~nm}$ with the absorption coefficient being significantly decreasing at wavelengths greater than $780 \mathrm{~nm}$. Note that the TiN nanoparticles that are $100 \mathrm{~nm}$ in radius have their plasmonic resonance peak at a wavelength of $880 \mathrm{~nm}$, indicating the high scattering capability of TiN in the IR range ${ }^{45}$. While the $75 \mathrm{~nm}$ radius 

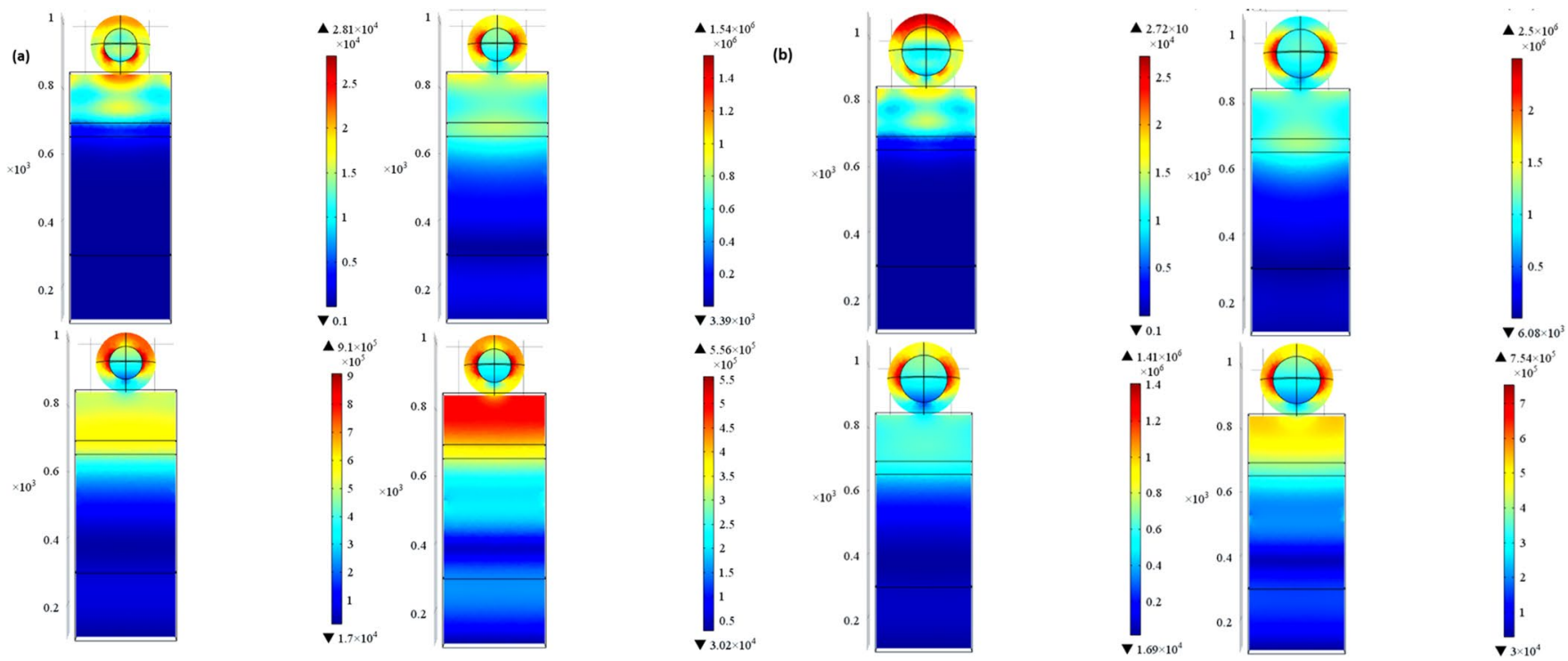

Figure 9. Electric field profiles of $\mathrm{ZrN} / \mathrm{SiO}_{2}$ core-shell-decorated PSCs: (a) $90 \mathrm{~nm}$ ( $50 \mathrm{~nm}$ core surrounded by $40 \mathrm{~nm}$ shell) and (b) $115 \mathrm{~nm}$ ( $75 \mathrm{~nm}$ core surrounded by $40 \mathrm{~nm}$ shell) at wavelengths of $300 \mathrm{~nm}, 800 \mathrm{~nm}$, $1000 \mathrm{~nm}$ and $1200 \mathrm{~nm}$, respectively.
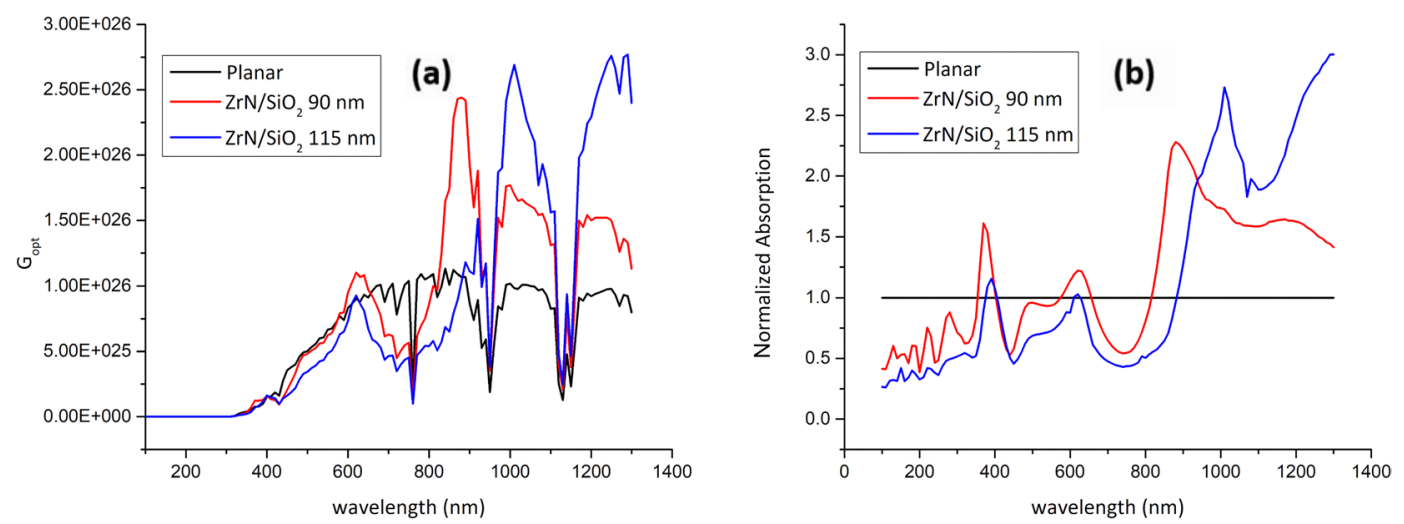

Figure 10. (a) Optical carrier generation rate $\left(G_{o p t}\right)$ and (b) normalized light absorption profiles for planar and $\mathrm{ZrN} / \mathrm{SiO}_{2}$-decorated PSCs.

\begin{tabular}{|l|l|l|l|l|l|l|}
\hline Structure & TGR $\left(\mathbf{m}^{-3} \mathbf{s}^{-1}\right)$ & TGR Enhancement & $\mathbf{J}_{\mathbf{s c}}\left(\mathbf{m A} / \mathbf{c m}^{2}\right)$ & $\mathbf{V}_{\text {oc }}(\mathbf{m V})$ & FF $(\%)$ & PCE (\%) \\
\hline Planar & $7.1840 \times 10^{27}$ & ---- & 27 & 680.5 & 70.2 & 12.9 \\
\hline $\mathrm{ZrN} / \mathrm{SiO}_{2}(90 \mathrm{~nm})$ & $9.1853 \times 10^{27}$ & $31 \%$ & 34.5 & 687.4 & 71.2 & 16.9 \\
\hline $\mathrm{ZrN} / \mathrm{SiO}_{2}(115 \mathrm{~nm})$ & $1.0721 \times 10^{28}$ & $55 \%$ & 40.3 & 691.4 & 71.8 & 20 \\
\hline
\end{tabular}

Table 3. The optical and electrical parameters of the $\mathrm{ZrN} / \mathrm{SiO}_{2}$-decorated PSCs.

TiN nanoparticles showed two plasmonic resonance peaks at $1000 \mathrm{~nm}$ and $1280 \mathrm{~nm}$, the $50 \mathrm{~nm}$ radius counterparts showed a resonance peak at $840 \mathrm{~nm}$. The TGR is calculated using Eq. 4 and listed in Table 1, indicating a maximum enhancement of $36.7 \%$ for the PSC decorated with $75 \mathrm{~nm}$ TiN particles compared to the planar PSC counterpart.

Figure $4 \mathrm{~b}$ shows the normalized absorption calculated using Eq. 5 for the simulated PSCs. TiN nanoparticles function as nano-antennas with their surface plasmon resonance (SPR) modes coupled to the PSC active layers due to the increase of the near field sunlight in the IR region $(>800 \mathrm{~nm})$. This absorption enhancement, especially in the IR bandwidth, due to the plasmonic nanoparticles effect to act as wave guide to direct sunlight by means of localized SPR, forming surface plasmon polaritons (SPP) at the air/TiN nanoparticle interface that couple sunlight into sub-wavelengths active area. 


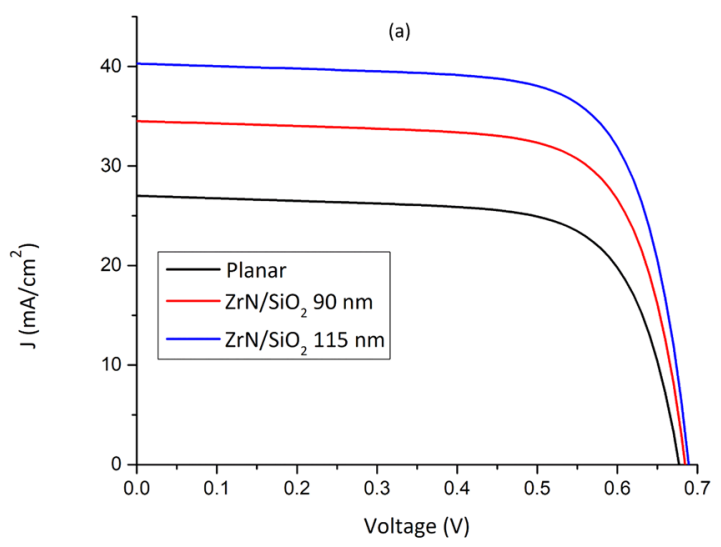

(b)

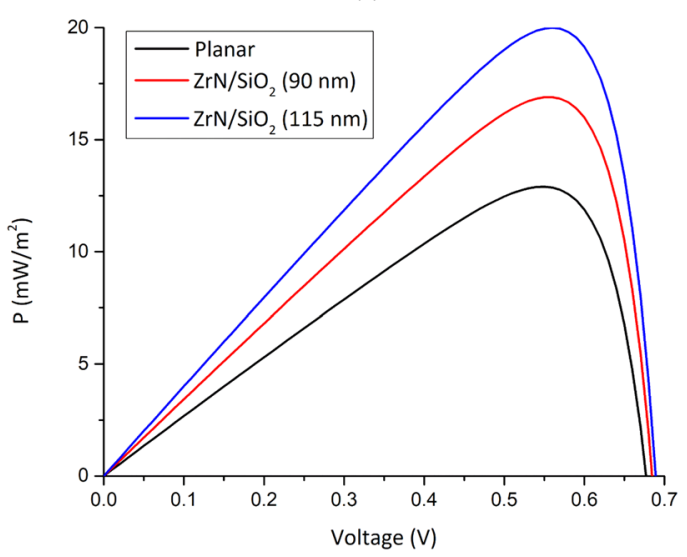

(c)

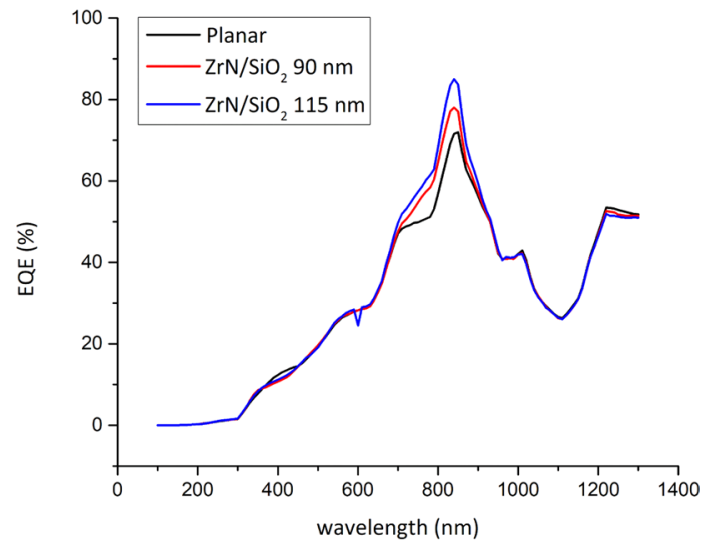

Figure 11. (a) $J-V$, (b) $P-V$, and (c) $E Q E$ characteristics of proposed $\mathrm{ZrN} / \mathrm{SiO}_{2}$-decorated PSCs.

The corresponding $J-V$ and $P-V$ characteristics of the simulated PSCs are shown in Fig. 5 and listed in Table 1. Note that the series and shunt resistances are tuned based on the reports in literature taking into account the recombination mechanisms in $\mathrm{PSCs}^{46}$. The optimized series resistance is found to be $50 \Omega$ and the shunt resistance is $400 \Omega$. The $J_{s c}$ shows a pronounced enhancement upon TiN-decoration compared to that of the planar PSC. The maximum enhancement in PEC is observed for the PSC decorated with the $100 \mathrm{~nm}$ TiN nanoparticles as it is increased from $12.9 \%$ for the planar PSC to $18.2 \%$, achieving ca. $41 \%$ enhancement in the overall solar cell efficiency. Figure $5 \mathrm{c}$ shows the EQE enhancement for each of the TiN-decorated PSCs. Note that the $100 \mathrm{~nm}$ TiN has an EQE of $85 \%$ due its high electric field directivity as shown in Fig. 2, where the localized surface plasmonic resonance of TiN nanoparticles is shown at $840 \mathrm{~nm}$, in agreement with Shalaev et al. ${ }^{33}$.

$\mathrm{ZrN}$-decorated PSCs. $\mathrm{ZrN}$ is another very promising refractory plasmonic material. The electric field profile for $\mathrm{ZrN}$ nanoparticles implanted onto the active layer of PSCs is shown in Fig. 6. Also, the $\mathrm{G}_{\mathrm{opt}}$ and the normalized 


\begin{tabular}{|l|l|l|l|l|l|}
\hline Parameters & TGR $\left(\mathbf{m}^{-3} \mathbf{s}^{-1}\right)$ & $\mathbf{J}_{\mathbf{s c}}\left(\mathbf{m A} / \mathbf{c m}^{2}\right)$ & $\mathbf{V}_{\text {oc }}(\mathbf{m V})$ & FF $(\%)$ & PCE $(\%)$ \\
\hline Planar & $7.18 \times 10^{27}$ & 27 & 680.5 & 70.21 & 12.9 \\
\hline $\mathrm{ZrN}(50 \mathrm{~nm})$ & $7.61 \times 10^{27}$ & 28.8 & 681.9 & 70.48 & 13.7 \\
\hline $\mathrm{ZrN}(75 \mathrm{~nm})$ & $8.59 \times 10^{27}$ & 32.6 & 685.1 & 70.96 & 15.7 \\
\hline $\mathrm{ZrN}(100 \mathrm{~nm})$ & $9.04 \times 10^{27}$ & 34.2 & 686.4 & 71.14 & 16.6 \\
\hline $\mathrm{TiN}(50 \mathrm{~nm})$ & $7.90 \times 10^{27}$ & 29.71 & 683.5 & 70.64 & 14.3 \\
\hline $\mathrm{TiN}(75 \mathrm{~nm})$ & $9.23 \times 10^{27}$ & 34.7 & 687.57 & 71.23 & 17 \\
\hline $\mathrm{TiN}(100 \mathrm{~nm})$ & $9.82 \times 10^{27}$ & 36.91 & 689.2 & 71.48 & 18.2 \\
\hline $\mathrm{ZrN} / \mathrm{SiO}_{2}(90 \mathrm{~nm})$ & $9.19 \times 10^{27}$ & 34.5 & 687.4 & 71.2 & 16.9 \\
\hline $\mathrm{ZrN} / \mathrm{SiO}_{2}(115 \mathrm{~nm})$ & $1.07 \times 10^{28}$ & 40.3 & 691.4 & 71.8 & 20 \\
\hline
\end{tabular}

Table 4. Comparison of optical and electrical parameters upon the use of different nanostructures.

optical absorption (NOA) are shown in Fig. 7. Note that the PSC decorated with $100 \mathrm{~nm}$ ZrN particles showed significant plasmonic resonance enhancement at the wavelengths of $1000 \mathrm{~nm}$ and $1250 \mathrm{~nm}$. Upon integrating the $\mathrm{G}_{\mathrm{opt}}$ over the swept simulated wavelength using Eq. 4, it was possible to calculate the total generation rate enhancement as listed in Table 2. Note that the $100 \mathrm{~nm} \mathrm{ZrN}$ particles showed $25.8 \%$ enhancement in the TGR compared to planar PSC with an increase in the PCE from 12.9\% (planar) to $16.6 \%$. Moreover, a maximum EQE of $84.63 \%$ at $840 \mathrm{~nm}$, compared to $72 \%$ for the planar PSC at the same wavelength, is observed, Fig. 8 .

Novel ZrN/SiO ${ }_{2}$ core/shell-decorated PSCs. $\quad \mathrm{ZrN} / \mathrm{SiO}_{2}$ core/shell structure has been tested as a novel structure to enhance the efficiency of PSC using two different radii of $\mathrm{ZrN}$ of $50 \mathrm{~nm}$ and $75 \mathrm{~nm}$ core surrounded by $40 \mathrm{~nm}$ of silica $\left(\mathrm{SiO}_{2}\right)$ shell. The core/shell structure is used as a means to tune the LSPR of $\mathrm{ZrN}$, which depends on the surrounding dielectric medium. Figure 9 shows the electric field profiles, indicating a great enhancement in the sunlight coupled to the solar cell active layer. Figure 10 shows a tremendous enhancement in the $G_{o p t}$ and optical absorption in the active layers of the PSCs upon the use of $\mathrm{ZrN} / \mathrm{SiO}_{2}$. Moreover, a $13.3 \mathrm{~mA} / \mathrm{cm}^{2}$ increase in $J_{s c}, 55 \%$ enhancement in the TGR, and an increase in the PCE from $12.9 \%$ to $20 \%$ are observed as listed in Table 3 and Fig. 11a,b. The EQE is $87 \%$ at $840 \mathrm{~nm}$ as recorded for the PSC decorated with $115 \mathrm{~nm} \mathrm{ZrN/SiO}$, see Fig. 11c.

Table 4 summarizes the calculated optical and electrical parameters of the PSCs-decorated with different refractory plasmonic nanoarchitectures. Note that the generation rate of $\mathrm{ZrN} / \mathrm{SiO}_{2}$ ( $75 \mathrm{~nm}$ core and $40 \mathrm{~nm}$ shell) increases by $19.8 \%$ and $15.7 \%$ compared to $\mathrm{ZrN}$ alone with $75 \mathrm{~nm}$ and $100 \mathrm{~nm}$ in radius, respectively. This can be ascribed to the enhancement in the plasmonic surface plasmon directivity by the dielectric shell.

\section{Conclusion}

In summary, refractory plasmonic materials (RPMs) have been investigated as a promising replacement to noble metals as nano-antennas to boost the photoconversion efficiency of lead-free perovskite solar cells. This was mainly based on the light trapping ability of the BPMs. The use of $\mathrm{ZrN}$ leads to a total generation rate enhancement of $25.8 \%$ with an increase in the PCE from $12.9 \%$ to $17 \%$. On the other hand, replacing ZrN with TiN shows a noticeable enhancement in the total generation rate of $18.2 \%$ with a PCE of $18.2 \%$. Tremendous enhancement in the optical and electrical characteristics of the PSCs are observed upon the use of $\mathrm{ZrN} / \mathrm{SiO}_{2}$ core/shell nanoparticles with a total generation rate enhancement of 55\% and an overall PCE of 20\%, which is yet to be achieved for any $\mathrm{Pb}$-free PSC. We hope our study opens a new avenue towards the realization of high efficiency Pb-free PSCs.

Received: 10 December 2019; Accepted: 6 April 2020;

Published online: 21 April 2020

\section{References}

1. Kojima, A., Teshima, K., Shirai, Y. \& Miyasaka, T. Organometal Halide Perovskites as Visible-Light Sensitizers for Photovoltaic Cells. Journal of the American Chemical Society 131, 6050-6051 (2009).

2. Kim, H.S. et al. Lead Iodide Perovskite Sensitized All-Solid-State Submicron Thin Film Mesoscopic Solar Cell with Efficiency Exceeding 9\%. Scientific Reports 2, (2012).

3. Lee, M. M., Teuscher, J., Miyasaka, T., Murakami, T. N. \& Snaith, H. J. Efficient Hybrid Solar Cells Based on Meso-Superstructured Organometal Halide Perovskites. Science 338, 643-647 (2012).

4. Shalan, A. E., El-Shazly, A. N., Rashad, M. M. \& Allam, N. K. Tin-zinc-oxide nanocomposites (SZO) as promising electron transport layers for efficient and stable perovskite solar cells. Nanoscale Advances 1, 2654-2662 (2019).

5. Yuan, L. et al. Semi-transparent perovskite solar cells: unveiling the trade-off between transparency and efficiency. Journal of Materials Chemistry A 6, 19696-19702 (2018).

6. Correa-Baena, J. P. et al. Homogenized halides and alkali cation segregation in alloyed organic-inorganic perovskites. Science 363, 627-631 (2019).

7. Yang, D., Yang, R., Priya, S. \& Liu, S. F. Recent Advances in Flexible Perovskite Solar Cells: Fabrication and Applications. Angewandte Chemie International Edition 58, 4466-4483 (2019).

8. Rajagopal, A., Yao, K. \& Jen, A. K.-Y. Toward Perovskite Solar Cell Commercialization: A Perspective and Research Roadmap Based on Interfacial Engineering. Advanced Materials 30, 1800455 (2018).

9. El-Shazly, A. N., Rezk, M. Y., Gameel, K. M. \& Allam, N. K. Electrospun Lead-Free All-Inorganic Double Perovskite Nanofibers for Photovoltaic and Optoelectronic Applications. ACS Applied Nano Materials 2, 7085-7094 (2019).

10. Zong, Y. et al. Continuous Grain-Boundary Functionalization for High-Efficiency Perovskite Solar Cells with Exceptional Stability. Chem 4, 1404-1415 (2018).

11. Ju, M. G. et al. Toward Eco-friendly and Stable Perovskite Materials for Photovoltaics. Joule 2, 1231-1241 (2018).

12. Green, M. A., Ho-Baillie, A. \& Snaith, H. J. The emergence of perovskite solar cells. Nature photonics 8(7), 506 (2014). 
13. Krishnamoorthy, T. et al. Lead-free germanium iodide perovskite materials for photovoltaic applications. Journal of Materials Chemistry A 3, 23829-23832 (2015).

14. Zuo, C. \& Ding, L. Lead-free Perovskite Materials (NH4)3Sb2IxBr9-x. Angewandte Chemie International Edition 56, 6528-6532 (2017).

15. Wang, N. et al. Solar Cells: Heterojunction-Depleted Lead-Free Perovskite Solar Cells with Coarse-Grained B- $\gamma$-CsSnI3 Thin Films. Advanced Energy Materials 6, (2016).

16. Hao, F., Stoumpos, C. C., Cao, D. H., Chang, R. P. H. \& Kanatzidis, M. G. Lead-free solid-state organic-inorganic halide perovskite solar cells. Nature Photonics 8, 489-494 (2014).

17. Stoumpos, C. C., Malliakas, C. D. \& Kanatzidis, M. G. Semiconducting Tin and Lead Iodide Perovskites with Organic Cations: Phase Transitions, High Mobilities, and Near-Infrared Photoluminescent Properties. Inorganic Chemistry 52, 9019-9038 (2013).

18. Jokar, E., Chien, C.-H., Tsai, C.-M., Fathi, A. \& Diau, E. W.-G. Robust Tin-Based Perovskite Solar Cells with Hybrid Organic Cations to Attain Efficiency Approaching 10\%. Advanced Materials 31, 1804835 (2018).

19. Paetzold, U. W., Qiu, W., Finger, F., Poortmans, J. \& Cheyns, D. Nanophotonic front electrodes for perovskite solar cells. Appl. Phys. Lett. 106(17), 173101 (2015).

20. Lermé, J. et al. Optical Properties of a Particle above a Dielectric Interface: Cross Sections, Benchmark Calculations, and Analysis of the Intrinsic Substrate Effects. The Journal of Physical Chemistry C 117, 6383-6398 (2013).

21. Nishimura, S. et al. Standing Wave Enhancement of Red Absorbance and Photocurrent in Dye-Sensitized Titanium Dioxide Photoelectrodes Coupled to Photonic Crystals. Journal of the American Chemical Society 125, 6306-6310 (2003).

22. Ito, S. et al. Fabrication of thin film dye sensitized solar cells with solar to electric power conversion efficiency over $10 \%$. Thin Solid Films 516, 4613-4619 (2008).

23. Schuck, P. J., Fromm, D. P., Sundaramurthy, A., Kino, G. S. \& Moerner, W. E. Improving the Mismatch between Light and Nanoscale Objects with Gold Bowtie Nanoantennas. Physical Review Letters 94, (2005).

24. Abdelraouf, O. A., Shaker, A. \& Allam, N. K. Front dielectric and back plasmonic wire grating for efficient light trapping in perovskite solar cells. Optical Materials 86, 311-317 (2018).

25. Kinkhabwala, A. et al. Large single-molecule fluorescence enhancements produced by a bowtie nanoantenna. Nature Photonics 3 , 654-657 (2009).

26. Kelzenberg, M. D., Putnam, M. C., Turner-Evans, D. B., Lewis, N. S. \& Atwater, H. A. Predicted efficiency of Si wire array solar cells. 2009 34th IEEE Photovoltaic Specialists Conference (PVSC) https://doi.org/10.1109/pvsc.2009.5411542 (2009).

27. Wang, W., Wu, S., Reinhardt, K., Lu, Y. \& Chen, S. Broadband Light Absorption Enhancement in Thin-Film Silicon Solar Cells. Nano Letters 10, 2012-2018 (2010).

28. Atwater, H. A. \& Polman, A. Plasmonics for improved photovoltaic devices. Nature Materials 9, 205-213 (2010).

29. Schmidt, M. A. \& Russell, P. S. Long-range spiralling surface plasmon modes on metallic nanowires. Optics Express 16, 13617 (2008).

30. Selmy, A. E., Soliman, M. \& Allam, N. K. Refractory plasmonics boost the performance of thin-film solar cells. Emergent Materials 1, 185-191 (2018).

31. Stuart, H. R. \& Hall, D. G. Absorption enhancement in silicon-on-insulator waveguides using metal island films. Applied Physics Letters 69, 2327-2329 (1996).

32. Guler, U., Shalaev, V. M. \& Boltasseva, A. Nanoparticle plasmonics: going practical with transition metal nitrides. Materials Today 18, 227-237 (2015).

33. El-Saeed, A. H. \& Allam, N. K. Refractory plasmonics: orientation-dependent plasmonic coupling in TiN and ZrN nanocubes. Physical Chemistry Chemical Physics 20, 1881-1888 (2018).

34. Kumar, M., Umezawa, N., Ishii, S. \& Nagao, T. Examining the Performance of Refractory Conductive Ceramics as Plasmonic Materials: A Theoretical Approach. ACS Photonics 3, 43-50 (2015).

35. Luo, Q. et al. Enhancing photovoltaic performance of perovskite solar cells with silica nanosphere antireflection coatings. Solar Energy 169, 128-135 (2018).

36. Shanmugapriya, T. \& Ramamurthy, P. Photoluminescence Enhancement of Nanogold Decorated CdS Quantum Dots. The Journal of Physical Chemistry C 117, 12272-12278 (2013).

37. Deceglie, M. G., Ferry, V. E., Alivisatos, A. P. \& Atwater, H. A. Design of Nanostructured Solar Cells Using Coupled Optical and Electrical Modeling. Nano Letters 12, 2894-2900 (2012).

38. Abdelraouf, O. A. \& Allam, N. K. Towards nanostructured perovskite solar cells with enhanced efficiency: Coupled optical and electrical modeling. Solar Energy 137, 364-370 (2016).

39. Rakić, A. D., Djurišić, A. B., Elazar, J. M. \& Majewski, M. L. Optical properties of metallic films for vertical-cavity optoelectronic devices. Applied Optics 37, 5271 (1998).

40. Roknuzzaman, M. et al. Insight into lead-free organic-inorganic hybrid perovskites for photovoltaics and optoelectronics: A firstprinciples study. Organic Electronics 59, 99-106 (2018).

41. Wang, X., Wu, G., Zhou, B. \& Shen, J. Optical Constants of Crystallized $\mathrm{TiO}_{2}$ Coatings Prepared by Sol-Gel Process. Materials 6 , 2819-2830 (2013).

42. Filipič, M., Löper, P., Niesen, B., De Wolf, S., Krč, J., Ballif, C. \& Topič, M. CH3NH3PbI3 perovskite/silicon tandem solar cells: characterization based optical simulations. Optics express 23(7), A263-A278 (2015).

43. König, T. A. F. et al. Electrically Tunable Plasmonic Behavior of Nanocube-Polymer Nanomaterials Induced by a Redox-Active Electrochromic Polymer. ACS Nano 8, 6182-6192 (2014).

44. Schnabel, V., Spolenak, R., Doebeli, M. \& Galinski, H. Structural Color Sensors with Thermal Memory: Measuring Functional Properties of Ti-Based Nitrides by Eye. Advanced Optical Materials 6, 1800656 (2018).

45. RIT Nanolithograpy Research Labs> Home Available at: http://www.rit.edu/lithography. (Accessed: July 2019).

46. Ke, W. et al. Efficient Lead-Free Solar Cells Based on Hollow \{en\}MASnI ${ }_{3}$ Perovskites. Journal of the American Chemical Society 139, 14800-14806 (2017).

47. Debbichi, L. et al. Perovskite Solar Cells: Mixed Valence Perovskite Cs2Au2I6: A Potential Material for Thin-Film Pb-Free Photovoltaic Cells with Ultrahigh Efficiency (Adv. Mater. 12/2018). Advanced Materials 30, 1870080 (2018).

48. Abdelraouf, O. A., Shaker, A. \& Allam, N. K. Novel design of plasmonic and dielectric antireflection coatings to enhance the efficiency of perovskite solar cells. Solar Energy 174, 803-814 (2018).

49. Lazemi, M., Asgharizadeh, S. \& Bellucci, S. A computational approach to interface engineering of lead-free CH3NH3SnI3 highlyefficient perovskite solar cells. Physical Chemistry Chemical Physics 20, 25683-25692 (2018).

50. Bishnoi, S. \& Pandey, S. K. Device performance analysis for lead-free perovskite solar cell optimisation. IET Optoelectronics 12, 185-190 (2018).

\section{Author contributions}

A.A.M. performed the calculations and analyzed the results. M.Z. and S.E.D.H. analyzed the results. N.K.A. proposed the idea, analyzed the results, and coordinated the project. All authors contributed to the writing of the manuscript. 


\section{Competing interests}

The authors declare no competing interests.

\section{Additional information}

Correspondence and requests for materials should be addressed to N.K.A.

Reprints and permissions information is available at www.nature.com/reprints.

Publisher's note Springer Nature remains neutral with regard to jurisdictional claims in published maps and institutional affiliations.

(c) (i) Open Access This article is licensed under a Creative Commons Attribution 4.0 International License, which permits use, sharing, adaptation, distribution and reproduction in any medium or format, as long as you give appropriate credit to the original author(s) and the source, provide a link to the Creative Commons license, and indicate if changes were made. The images or other third party material in this article are included in the article's Creative Commons license, unless indicated otherwise in a credit line to the material. If material is not included in the article's Creative Commons license and your intended use is not permitted by statutory regulation or exceeds the permitted use, you will need to obtain permission directly from the copyright holder. To view a copy of this license, visit http://creativecommons.org/licenses/by/4.0/.

(c) The Author(s) 2020 